\title{
Pain Relief in Labour: How Can We Improve Intrapartum Care?
}

\author{
Sally Byford ${ }^{1}$, Edward Weaver ${ }^{1,2}$ \\ ${ }^{1}$ Nambour General Hospital, Nambour, Australia \\ ${ }^{2}$ University of Queensland, Brisbane, Australia \\ Email: sallybyford@doctors.org.uk
}

How to cite this paper: Byford, S. and Weaver, E. (2016) Pain Relief in Labour: How Can We Improve Intrapartum Care? Open Journal of Obstetrics and Gynecology, 6, 785-793.

http://dx.doi.org/10.4236/ojog.2016.613096

Received: June 23, 2016

Accepted: December 3, 2016

Published: December 6, 2016

Copyright $\odot 2016$ by authors and Scientific Research Publishing Inc. This work is licensed under the Creative Commons Attribution International License (CC BY 4.0).

http://creativecommons.org/licenses/by/4.0/ (c) (i) Open Access

\section{Abstract}

Background: Pain in labour is perceived differently for every individual. We can improve the outcomes and patient satisfaction with intrapartum care by ensuring adequate education and appropriate use of requested pain relief options. Encouraging informed personal control contributes to a women's overall satisfaction. Aims: To assess current practice and identify improvement areas in the perception, planning and use of pain relief options, and how this impacts satisfaction of pain relief in labour. Methods: 114 retrospective anonymous patient questionnaires were returned by women delivering by spontaneous vaginal delivery, instrumental delivery or emergency caesarean section at Nambour General Hospital between April and July 2011. Data were collated and analysed using STATA. Results: $83 \%$ and $65 \%$ of women had their pain relief options explained antenatally and on admission respectively. $92 \%$ reported their pain relief was adequately provided. There was a significant difference ( $\mathrm{p}<<0.001$ ) between those reporting "very good" or "good" satisfaction when compared to those reporting "fair" or "poor" with regards to a change from their method of planned pain relief. However, no significant difference $(\mathrm{p}=0.62)$ between the "same as planned" group and the "different than planned" group, highlighting that most women were satisfied irrespective of whether their plan changed or not. However, if they were unsatisfied, this correlated with a change in their plan. Conclusions: Education of pain relief options for labour antenatally and on birth suite admission, with adequate discussion and documentation of their wishes encourages informed planning and use of pain relief. This promotes personal choice and control, resulting in improved overall satisfaction of pain relief in labour.

\section{Keywords}

Pain Relief, Childbirth, Labour 


\section{Background}

Pain in labour is perceived differently by every woman, and is dependent on many factors, including physical, emotional, cognitive, social and cultural influences. However, two points seem clear: there is a wide variation in the pain perceived by women, and most women in labour can experience significant levels of pain [1].

Pain during childbirth is often regarded differently from pain in other clinical circumstances, with some hypothesizing that pain is a "good" pain which induces an important physiological process in labour namely, the release of natural endorphins, that help women cope with high levels of pain [2]. Other evidence has shown adverse effects of unrelieved pain which include hyperventilation leading to respiratory alkalosis and potential fetal hypoxia increased catecholamine release causing vasoconstriction of placental vessels and a relationship with increased rates of post-natal depression [3] [4] [5].

In the UK, the General Medical Council publication "Duties of a Doctor" states that doctors have a duty to "take steps to alleviate pain and distress", and The American College of Obstetrics and Gynaecology (ACOG) point out that labour is unique in medicine because "there is no other circumstance in which it is considered acceptable to experience pain that is amenable to safe relief while under a physician's care" [6] [7]. It has also been stated that "the strongest arguments in favour of medical pain relief in childbirth by systemic opioids or epidural anaesthesia are usually advanced by doctors who do not spend much time in the labour rooms themselves" [8]. Further it has been shown that "one on one" maternity care by a known carer has been shown to reduce analgesic requirements [9]. Given these varying views, it would seem preferable to individualise pain relief provided to each woman in labour according to her clinical circumstances.

McCrea and Wright showed that personal control during labour positively affected the women's satisfaction with any pain relief used [10]. Thus informing and educating women adequately in the antenatal period regarding their pain relief choices, and then offering them control of these options may help to improve a women's satisfaction with the way that her pain relief in labour is managed. The Cochrane overview of systematic reviews considering pain management in labour concluded that women should feel free to choose whatever pain management they feel would help them best, and highlighted that although evidence shows pharmacological pain relief is effective, it can also be associated with adverse effects for the mother and baby [11].

\section{Introduction}

Nambour General Hospital (NGH) is a secondary level hospital in Queensland catering for around 2800 births per annum. Care is provided via different models of care; these include midwife care with the support of obstetric staff for low risk women, and a medical model of care for higher risk patients, with midwifery input. Labour ward practice at Nambour General Hospital does not currently follow a set protocol for pain relief in labour, although State Maternity and Neonatal Network Guidelines have been pub- 
lished, which inform the hospital's practice [12]. Currently women in labour are cared for by a midwife participating in team care, with the opportunity to escalate care as the clinical needs of the woman change. Following a labour ward audit, most midwives reported that they did discuss pain relief options when they first admitted a woman in labour to the Birth Suite.

At a clinical review meeting, most midwives stated that they would not offer pain relief routinely to a woman admitted in labour. The most common reasons given for this practice was that they felt that offering pain relief may make the woman feel that, in the midwife's opinion, they were not coping with labour and that this may influence subsequent personal control and analgesic requirements. They further explained that they would implement any pain relief choices the women asked for, following some discussion, within limitations of best practice and labour progress.

However, there were times when clinical situations evolved, a lack of communication between the midwife and other team members occurred, or other factors arose that had a negative impact on how the women perceived their overall birth experience.

Thus, it was felt important to look retrospectively at the adequacy of the provision of suitable, timely pain relief in labour, and how this may have been influenced by antenatal preparation and the philosophy of the midwife involved in her care.

\section{Aims and Objectives}

Primary outcomes:

To determine whether patients are adequately informed prospectively-either antenatally and/or on admission to the Birth Suite of their pain relief options in labour.

To determine whether patients would prefer to be offered, or ask for, drugs for pain relief.

To determine a cohort of patients' overall satisfaction with their pain relief in labour. Secondary outcomes:

What drug options for pain relief were ultimately used, and how did this differ from what had been planned antenatally?

Whether patients felt able to ask for pain relief?

Whether patients felt encouraged to have pain relief they did not want?

Whether being offered pain relief would make patients feel that they were more likely to use it?

Was overall satisfaction of labour care influenced by whether pain relief expectations were met?

\section{Methods}

Women on the postnatal ward of Nambour General Hospital between 22nd April 2011 and 16th July 2011 were given a retrospective anonymous patient questionnaire. Women who delivered by elective caesarean section were excluded. Some eligible women did not receive a questionnaire due to early discharge, or inpatient stay over the weekend. Therefore 323 out of 454 (71\%) of women who delivered by spontaneous vaginal 
delivery, instrumental delivery or emergency caesarean section. received a questionnaire. 114 anonymous questionnaires were returned (35\%) by the patients to a locked box. The questionnaires were collected and the information collated in a spreadsheet. The pain relief options that were assessed were: no pain relief apart from psychological support, sterile water injections, nitrous oxide, narcotic injections and an epidural.

Data was displayed as whole numbers and proportions. Patient satisfaction and its correlation with the patient's plan was analysed using the Fisher's Exact test for $2 \times 2$ contingency data, and the Mann-Whitney $U$ test for grouped data. All data were analysed using STATA (v12.0) and P $=0.05$ was taken as significant.

Ethical approval was granted by The Prince Charles Hospital Human Research Ethics Committee Executive. Reference: HREC/12/QPCH/248.

\section{Results}

53\% patients were multiparous, $46 \%$ primiparous and 1 patient did not answer this question. $75 \%$ had a spontaneous vaginal delivery, $11 \%$ an instrumental delivery, $13 \%$ an emergency Caesarean section, and $1 \%$ did not answer. The population characteristics are described in Table 1.

$83 \%$ of women answered that their pain relief options were discussed with them antenatally, and $65 \%$ on admission to birth suite. $11 \%$ and $21 \%$ respectively perceived that these options were not discussed with them.

$50 \%$ of people reported that they would rather ask for pain relief, while $32 \%$ would prefer to be offered, and $17 \%$ would like to both ask and be offered.

Overall satisfaction was reported as follows: $46 \%$ "very good", $38 \%$ "good", $9 \%$ "fair" and 1\% "poor"-see Table 2. 7 women did not answer regarding overall satisfaction or

Table 1. Population characteristics.

\begin{tabular}{ccc}
\hline & Characteristic & Percentage of Women \\
\hline Parity & Primparous & 46 \\
Multiparous & No answer & 53 \\
Mode of Delivery & & 1 \\
& Sponaneous vaginal delivery & 75 \\
Instrumental delivery & Caesarean section & 11 \\
Type of antenatal care & No answer & 13 \\
& & 1 \\
& Midwife & 48 \\
& General Practioner & 40 \\
Obstetrician & 6 \\
Other & No answer & 4 \\
\hline
\end{tabular}


reported not applicable. Most comments regarding this were based around lack of time for requested pain relief option at their stage of labour.

More women used each type of pain relief than had planned to-for example, 3 more women used sterile water injections than had planned to, 8 more used nitrous oxide, 7 more used pethidine and 2 more used an epidural. Only 4 women who had planned to use no pain relief ended up using some method of analgesia Figure 1.

105 out of the 114 women $(92.1 \%)$ felt that their pain was adequately attended to, with only $2(1.8 \%)$ women responding negatively, and 7 not answering. $94.7 \%$ of women felt that they were able to ask for pain relief. However, $4.4 \%$ reported that they felt they were not able to ask for pain relief and 2.6\% (3) women did not respond. Only $3.5 \%$ (4) women reported that they felt encouraged or pressured to have pain relief they did not wish Figure 2.

When asked whether being offered pain relief would make them feel that they would be more likely to use it, $39.5 \%$ replied yes, $38.5 \%$ said no, and $21.2 \%$ were unsure, $0.9 \%$

Table 2. Levels of overall satisfaction with pain relief in labour.

\begin{tabular}{cc}
\hline Overall Satisfaction & Number of Women $\mathrm{n}=114(\%)$ \\
\hline Very good & $53(46)$ \\
Good & $43(38)$ \\
Fair & $10(9)$ \\
Poor & $1(1)$ \\
Other & $7(6)$ \\
\hline
\end{tabular}

Pain relief drugs: Planned/Used

Planned Used

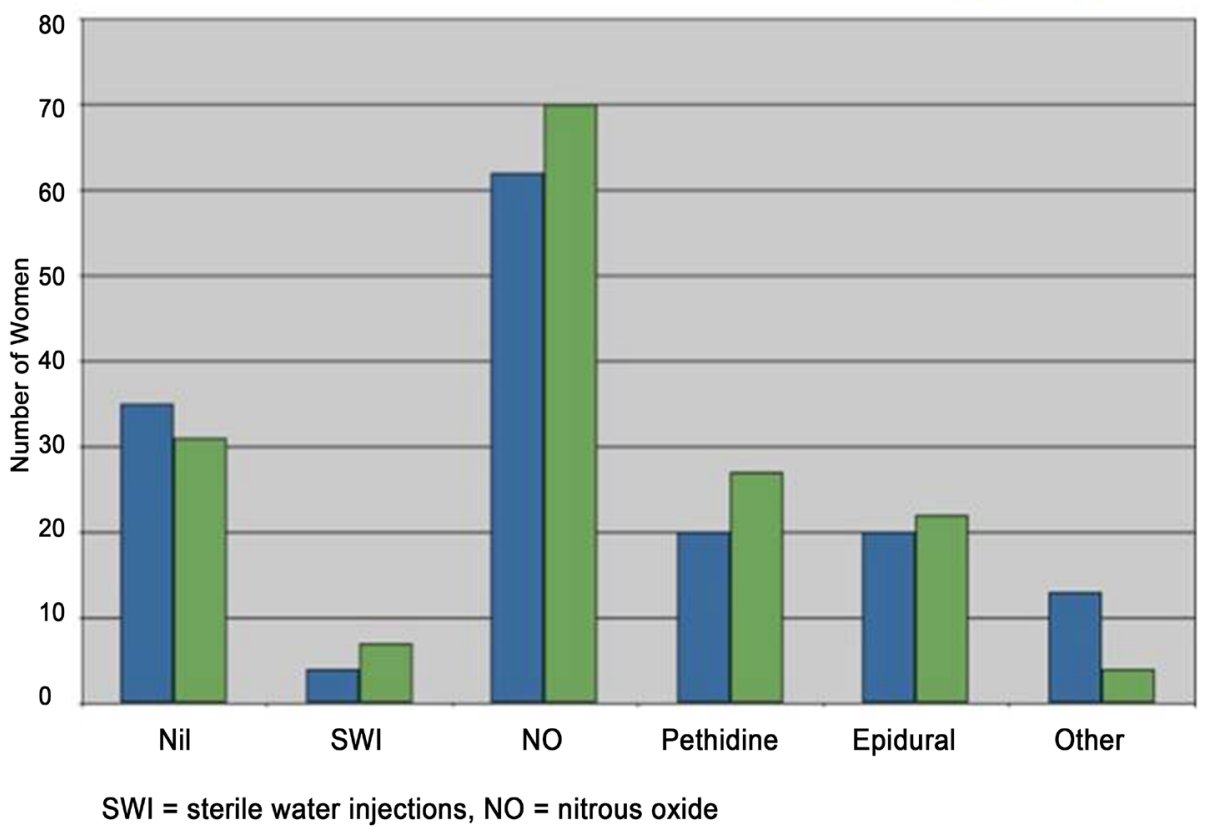

Figure 1. Pain relief methods used. 


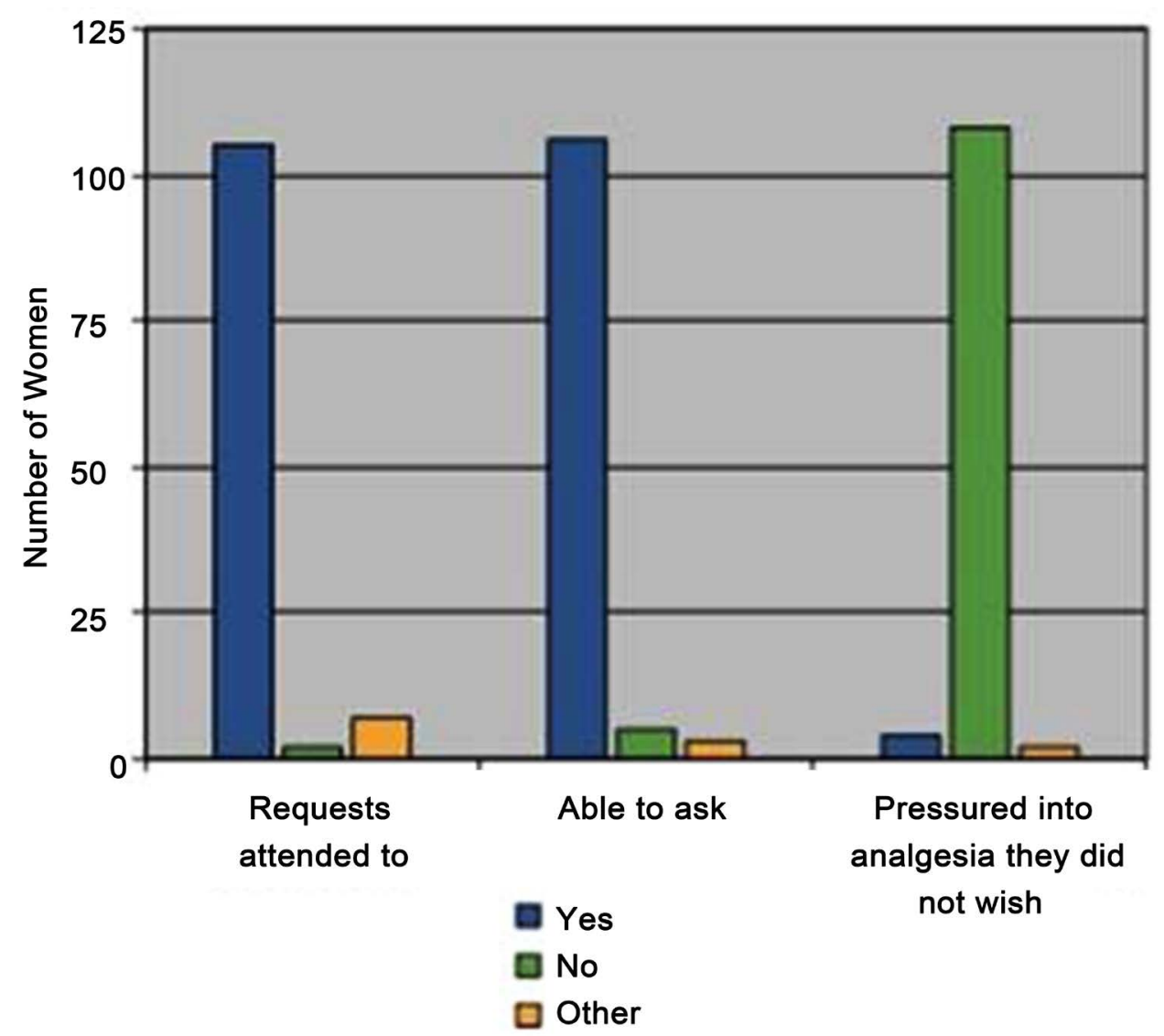

Figure 2. Women's views on pain relief provision.

did not answer.

How women rated their overall satisfaction with their planned pain relief is outlined in Table 3 and Figure 3. Of those women who used the pain relief options that they had planned, 24 rated their overall experience as "very good", 22 responded "good" and 1 "fair". In those women whose actual pain relief used differed from what they had planned, 22 reported their experience as "very good", 18 as "good", 8 as "fair" and 1 as "poor". 11 women wrote 'no plan', and of them, they responded 7 "very good", 3 "good" and 1 "fair". 7 women did not rate their overall experience.

There was a significant difference ( $\mathrm{p}<<0.001)$ between those reporting "very good" or "good" when compared to "air" or "poor" satisfaction with a change from their planned pain relief used. However, there was no significant difference $(p=0.62)$ in overall satisfaction between the "same as planned" group and the "different than planned" group, highlighting that most women were satisfied irrespective of whether their plan changed or not. However, if they were unsatisfied, this correlated with a change in their plan.

\section{Discussion}

Labour and delivery is unique for each woman, and for every situation it is important 

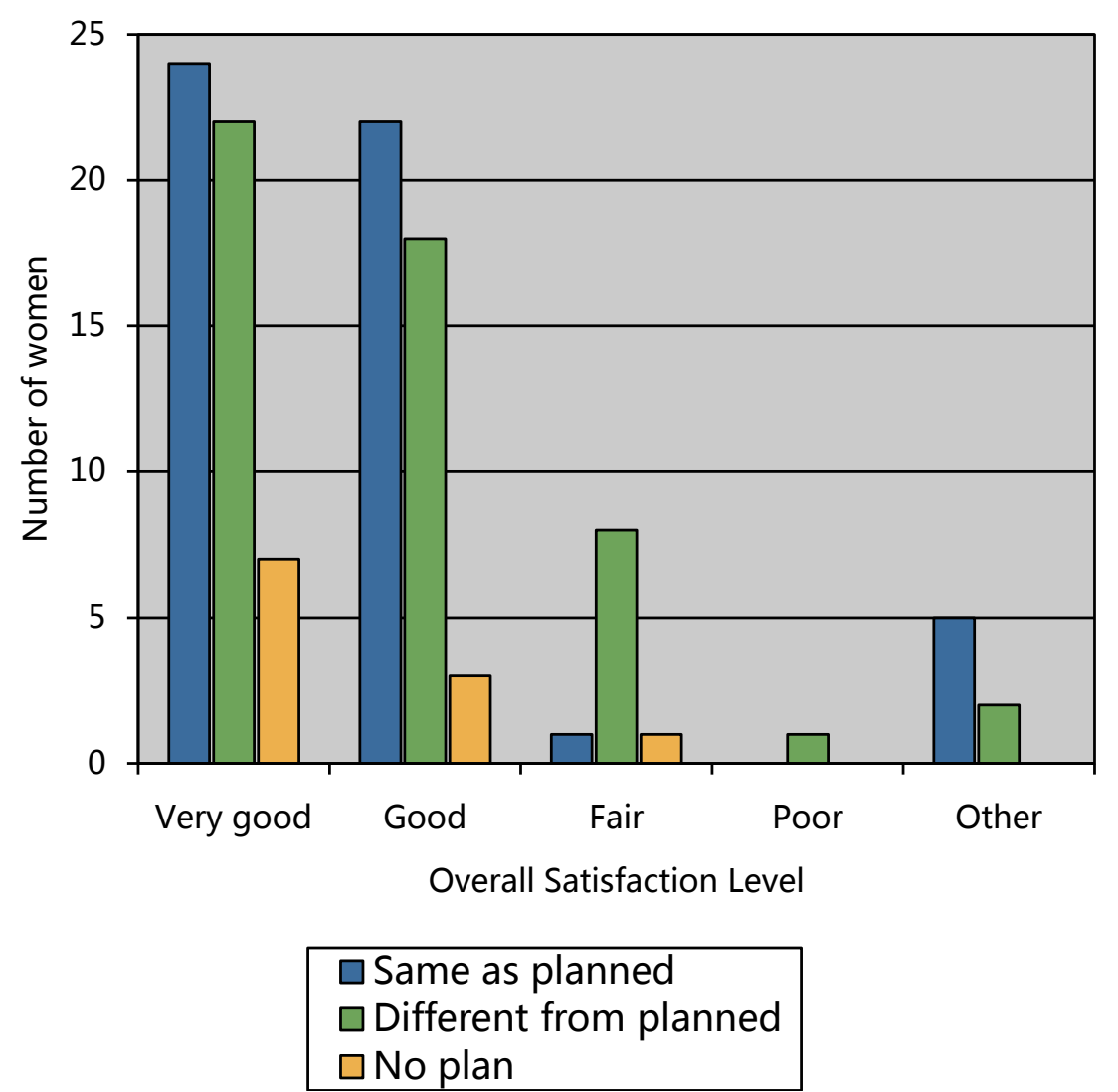

Figure 3. How change to perceived plan affected overall satisfaction.

Table 3. How changes to planned pain relief affects satisfaction level.

\begin{tabular}{cccc}
\hline $\begin{array}{c}\text { Overall } \\
\text { Satisfaction }\end{array}$ & $\begin{array}{c}\text { Used same pain relief options } \\
\text { as planned }(\mathrm{n}=52)\end{array}$ & $\begin{array}{c}\text { Used different pain relief options } \\
\text { than planned }(\mathrm{n}=51)\end{array}$ & No plan $(\mathrm{n}=11)$ \\
\hline Very good & 24 & 22 & 7 \\
Good & 22 & 18 & 3 \\
Fair & 1 & 8 & 0 \\
Poor & 0 & 1 & 0 \\
Other & 5 & 2 & 0 \\
\hline
\end{tabular}

to be able to adapt maternity care practice to those changing circumstances. However informing and educating women antenatally is essential to best prepare them for this time. Dedicated antenatal classes facilitated by trained midwives are a common way to deliver such education.

Overall, women in this study seem divided on whether they would rather be offered or ask for pain relief in labour-this suggests that every situation is different and that care should be individualized. The majority felt their options were discussed antenatally, but only $65 \%$ reported discussion on admission to birth suite. Of note it would seem that midwives' concerns over early discussion of pain relief options leading to increased use was unfounded in this group. By stipulating a discussion, with documentation, be- 
tween the attending midwife and the woman, on admission to birth suite, about options and preferences for pain relief in labour, practice would be more informative, collaborative and patient-centered and may improve a woman's overall satisfaction with her care.

Goodman et al. demonstrated that personal control in labour was a statistically significant predictor of total satisfaction, and remembering the first ethical principle of autonomy: a patient's right to choose-we should remember that whatever decision is made by a patient, following provision of appropriate information about progress in labour and pain relief options, we, as a team, should respect those individual decisions [13]. The Cochrane review showed that while pain intensity was reviewed in many trials, patient satisfaction with pain relief \& childbirth experience, as well as sense of control in labour were much less commonly addressed [11]. Our study agrees with previous findings that patients who had overall good experiences in childbirth had not deviated from their planned pain relief options, indicating that personal control is an important factor.

The main limitation of this audit is its small sample size. Reasons for this included the fact that not all women who delivered during the timeframe and met criteria were given a questionnaire, mainly due to early discharge. There were a significant number of incomplete questionnaires-30. The intact data from these was included to preserve sample size. However, given it was an anonymous questionnaire the $35 \%$ response rate was relatively good when compared with similar studies.

The questionnaire is a retrospective study, subjective and dependent on memories of a time that may have been stressful. For example, a midwife may have felt they made the pain relief options clear on admission to birth suite, however the women may not remember or have understood the discussion at the time. Also, certain types of deliveries require different sorts of analgesia-Caesarean section requires regional or general anaesthetic and women may have erroneously chose "epidural" when a spinal anaesthetic was used. By specifying that an epidural was used prior to the decision for Caesarean section would have made this point clearer.

When women present in labour, a check-box on the front of the partogram may help to ensure women receive adequate information about their pain relief options. This could highlight whether the options were discussed, and the women's preferences for pain relief to be offered or requested. This may ensure better continuity of care and would provide clear documentation of a woman's wishes for midwives and doctors that may be involved in her care, encouraging patient control. Multidisciplinary care and good communication between midwives, obstetricians and anaesthetists are required in adequately informing, educating and supporting women in their choices with regards to pain relief in labour.

\section{Conclusion}

In conclusion, this study demonstrated a correlation between a higher level of satisfaction of overall labour experience with no deviation from a woman's pain relief plan. This highlights the importance of antenatal education to make women aware of their options, and communication in the birth suite to ensure women's wishes are unders- 
tood. It also highlighted that if women were dissatisfied with their pain relief in labour, then this was associated with a change in their anticipated pain relief plan, demonstrating that patient control in labour is an important determinant in a woman's overall satisfaction with her labour care, irrespective of type of pain relief used.

\section{Acknowledgements}

Dr Chris Anstey for his assistance with statistical analysis.

\section{References}

[1] Caton, D., et al. (2002) The Nature and Management of Labor Pain: An Executive Summary. American Journal of Obstetrics \& Gynecology, 186, S1-S5.

[2] Leap, N. and Anderson, T. (2004) The Role of Pain in Normal Birth and the Empowerment of Women. In: Downe, S., et al., Eds., Normal Childbirth: Evidence and Debate, Churchill Livingstone, Edinburgh, 25-39.

[3] Ralston, D.H., Shnider, S.M. and De Lorimier, A.A. (1974) Uterine Blood Flow and Fetal Acid-Base Changes after Bicarbonate Administration to the Pregnant Ewe. Anesthesiology, 40, 348. http://dx.doi.org/10.1097/00000542-197404000-00008

[4] Shnider, S.M., Wright, R.G., Levinson, G., Roizen, M.F., Wallis, K.L., Rolbin, S.H. and Craft, J.B. (1979) Uterine Blood Flow and Plasma Norepinephrine Changes during Maternal Stress in the Pregnant Ewe. Anesthesiology, 50, 524. http://dx.doi.org/10.1097/00000542-197906000-00010

[5] Hiltunen, P., Raudaskoski, T., Ebeling, H. and Moilanen, I. (2004) Does Pain Relief during Delivery Decrease the Risk of Postnatal Depression? Acta Obstetricia et Gynecologica Scandinavica, 83, 257. http://dx.doi.org/10.1111/j.0001-6349.2004.0302.x

[6] General Medical Council. Good Medical Practice: Providing Good Clinical Care. 2012. http://www.gmc-uk.org/guidance/good_medical_practice/good_clinical_care_index.asp

[7] Goetzl, L.M., ACOG Committee on Practice Bulletins-Obstetric (2002) ACOG Practice Bulletin. Number 36, July 2002. Obstetric Analgesial and Anesthesia. Obstetrics \& Gynecology, 100, 177-191. http://dx.doi.org/10.1016/S0029-7844(02)02156-7

[8] O’Driscoll, K., et al. (2003) Active Management of Labour. 4th Edition, Mosby, New York.

[9] Hodnett, E., et al. (2007) Cochrane Review: Continuous Support for Women during Childbirth. Cochrane Database of Systematic Reviews, 3, Article ID: CD003766. http://dx.doi.org/10.1002/14651858.CD003766.pub2

[10] McCrea, B.H. and Wright, M.E. (1999) Satisfaction in Childbirth and Perceptions of Personal Control in Pain Relief during Labour. Journal of Advanced Nursing, 29, 877. http://dx.doi.org/10.1046/j.1365-2648.1999.00961.x

[11] Jones, L., Othman, M., Dowswell, T., Alfirevic, Z., Gates, S., Newburn, M., Jordan, S., Lavender, T. and Neilson, J.P. (2012) Pain Management for Women in Labour: An Overview of Systematic Reviews. Cochrane Database of Systematic Reviews, 3.

[12] http://www.health.qld.gov.au/qcg/documents/g_normbirth.pdf

[13] Goodman, P., Mackey, M.C. and Tavakoli, A.S. (2004) Factors Related to Childbirth Satisfaction. Journal of Advanced Nursing, 46, 212-219. http://dx.doi.org/10.1111/j.1365-2648.2003.02981.x 
Submit or recommend next manuscript to SCIRP and we will provide best service for you:

Accepting pre-submission inquiries through Email, Facebook, LinkedIn, Twitter, etc. A wide selection of journals (inclusive of 9 subjects, more than 200 journals)

Providing 24-hour high-quality service

User-friendly online submission system

Fair and swift peer-review system

Efficient typesetting and proofreading procedure

Display of the result of downloads and visits, as well as the number of cited articles

Maximum dissemination of your research work

Submit your manuscript at: http://papersubmission.scirp.org/

Or contact ojog@scirp.org 